University of Nebraska - Lincoln

DigitalCommons@University of Nebraska - Lincoln

Roman L. Hruska U.S. Meat Animal Research

U.S. Department of Agriculture: Agricultural Center

Research Service, Lincoln, Nebraska

2001

\title{
Structure of the Genes for Porcine Endometrial Secreted and Membrane Folate Binding Proteins
}

J. L. Vallet

USDA-ARS, vallet@email.marc.usda.gov

T. P. L. Smith

USDA-ARS, tim.smith@ars.usda.gov

T. S. Sonstegard

USDA-ARS

M. Heaton

USDA-ARS, mike.heaton@usda.gov

S. C. Fahrenkrug

USDA-ARS

Follow this and additional works at: https://digitalcommons.unl.edu/hruskareports

Vallet, J. L.; Smith, T. P. L.; Sonstegard, T. S.; Heaton, M.; and Fahrenkrug, S. C., "Structure of the Genes for Porcine Endometrial Secreted and Membrane Folate Binding Proteins" (2001). Roman L. Hruska U.S. Meat Animal Research Center. 256.

https://digitalcommons.unl.edu/hruskareports/256

This Article is brought to you for free and open access by the U.S. Department of Agriculture: Agricultural Research Service, Lincoln, Nebraska at DigitalCommons@University of Nebraska - Lincoln. It has been accepted for inclusion in Roman L. Hruska U.S. Meat Animal Research Center by an authorized administrator of DigitalCommons@University of Nebraska - Lincoln. 


\title{
Structure of the genes for porcine endometrial secreted and membrane folate binding proteins
}

\author{
J.L. Vallet*, T.P.L. Smith, T.S. Sonstegard, M. Heaton, S.C. Fahrenkrug \\ USDA, ARS, Roman L. Hruska U.S. Meat Animal Research Center, Clay Center, NE, USA
}

Received 14 March 2001; accepted 4 April 2001

\begin{abstract}
The endometrium of the pig produces two types of folate binding proteins (FBP) which, based on their sequences, are likely to be membrane $(\mathrm{m})$ and secreted (s) forms. A clone containing both a gene coding for the sFBP cDNA and a gene coding for the mFBP was isolated from a yeast artificial chromosome (YAC) library. Each gene was subcloned and sequenced. The gene for sFBP spanned 4.4 $\mathrm{kbp}$ and included 5 exons. The mFBP gene spanned $7.0 \mathrm{kbp}$ and also contained 5 exons. Structures of the genes were very similar for the last three exons, and this similarity was shared with other known FBP/folate receptor (FR) gene sequences. Unexpectedly, portions of introns 3 and 4 of both genes were highly homologous, suggesting the possibility that sequences within these introns served some as yet unknown function. In contrast, the structures of the $5^{\prime}$ exons differed between the two genes and other known FBP/FR genes. Comparison of putative promoter regions for the two genes with promoter regions for human FBP/FR genes revealed significant sequence homology between sFBP and human $\gamma \mathrm{FBP}$ and between mFBP and human $\alpha \mathrm{FR}$. These regions of homology may play a role in control of transcription of each gene. (C) 2001 Elsevier Science Inc. All rights reserved.
\end{abstract}

\section{Introduction}

Folates are vitamins that participate in methyl transfer reactions and are essential for methionine and DNA synthesis [1]. Consequently, rapidly growing tissues, such as the erythron and the developing conceptus, have a high requirement for folate, and deficiencies lead to abnormal erythropoiesis [2] and birth defects [3]. In swine, folate transport to the developing conceptus is not well understood, but recent evidence suggests that two different

\footnotetext{
* Corresponding author. Tel.: +1-402-762-4187; fax: +1-402-762-4382.
}

E-mail address: vallet@email.marc.usda.gov (J.L. Vallet). 
Table 1

Primers used for screening and PCR cloning of portions of the FBP genes

YAC screening

Forward A

GAGTGCTCGCCCAACCTG

Reverse B

AGTAGAAGTCGAAGCGGTGGC

SFBP cosmid screening

5 sec FBP-F1

5 sec FBP-R1

AAAGCTCAGACTGCACTGTCC

mFBP primers

CAGATTTCCTGTTTCCCTTCC

$5^{\prime}$ cosmid screening

5mem FBP-F1

5mem FBP-R-1

GGATTCCTGCTGCTTTTGAC

$3^{\prime}$ cosmid screening

COSMFBP-F3

COSMFBP-R2

TCATGCAGGCCATCTTCC

PCR Cloning

MEMGEN-5

FBPRCE-R2

GCCTGGCCTCTCCAGTTC

TAGAGGCACTGACGAGCTG

GCGCTGATCTGGCAACTC

TTCCCACCAGTTCTGACAGTC

forms of folate binding protein (FBP), a secreted (s) and a membrane (m) form, likely play central roles in this process during early pregnancy $[4,5]$.

The sFBP is a 30,000 Mr protein that appears as a diffuse band after SDS-PAGE and Coomassie blue staining [4]. It binds folic acid with high affinity, and increases from Day 11 to Day 13 of the cycle or pregnancy to reach $\mu \mathrm{g} / \mathrm{ml}$ concentrations within the intrauterine lumen $[4,6]$. This increase in sFBP within the intrauterine lumen occurs in the absence of obvious changes in the amount of mRNA present in endometrium [5]. Cloning and sequencing of the cDNA for this protein indicated that it was related to other FBP/folate receptor (FR) cDNAs previously characterized, but differs from the porcine FR described previously [7]. Heterogeneity of the $5^{\prime}$ untranslated region (UTR) was also demonstrated, likely due to differential mRNA splicing [6].

A putative mFBP cDNA was also isolated from endometrium along with the cDNA for sFBP [6]. The membrane linkage of this protein was predicted due to the presence of an intact glycophosphatidylinositol linkage site $[5,8]$. The mFBP cDNA shares sequence homology with the sFBP cDNA as well as with other known FBP/FR cDNAs. The mRNA for $\mathrm{mFBP}$ is present in a variety of tissues and expression increases dramatically from Day 15 to Day 24 in endometrium from pregnant pigs. It is also relatively highly expressed in Day 30 placental tissue. The 5' UTR of this cDNA is also heterogeneous, probably due to differential splicing [5]. The mFBP protein itself has not yet been characterized.

To obtain clues to the control of production of these proteins in the intrauterine environment of swine during pregnancy and to determine the basis of the heterogeneity of the $5^{\prime}$ UTRs for each cDNA, we cloned and sequenced the genes corresponding to each cDNA.

\section{Materials and methods}

A yeast artificial chromosome (YAC) genomic library was screened by PCR using primers capable of amplifying either gene (Table 1). Screening yielded one positive YAC clone that 


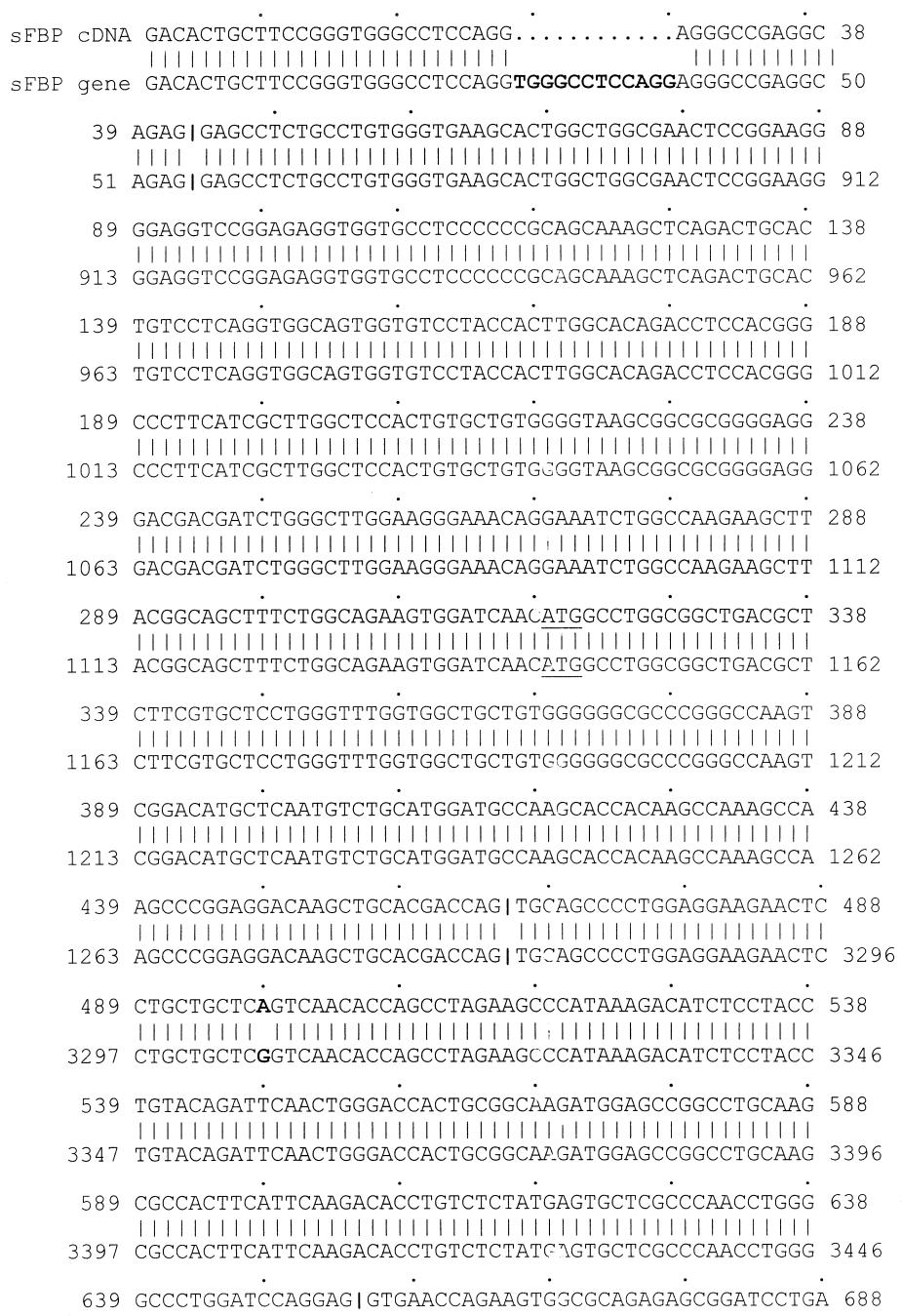

Fig. 1. The sFBP and mFBP cDNA sequences aligned with their respective gene sequences are illustrated. Mismatched nucleotides are indicated in bold. The start and stop codons are underlined. For sFBP, the cDNA sequence at $913 \mathrm{bp}$ codes for a serine while the gene codes for an arginine residue. All other mismatches do not affect the predicted amino acid sequence.

was found to contain both genes upon PCR analysis using primers specific to the $5^{\prime}$ end of each cDNA (Table 1; 5). The YAC incorporating the FBP genes was isolated by pulse field electrophoresis and then partially digested with SauIIIa to generate fragments of a suitable size for cosmid cloning. Fragments were gel isolated, ligated with the superCOS vector, and the resulting DNA was packaged and bacteria were infected according to the directions contained in the Gigapack III packaging kit (Stratagene, La Jolla, CA). Resultant colonies were screened with primers specific to the $5^{\prime}$ ends of each gene. A positive clone for the sFBP gene containing the entire gene and a positive clone containing only the $5^{\prime}$ end of the 


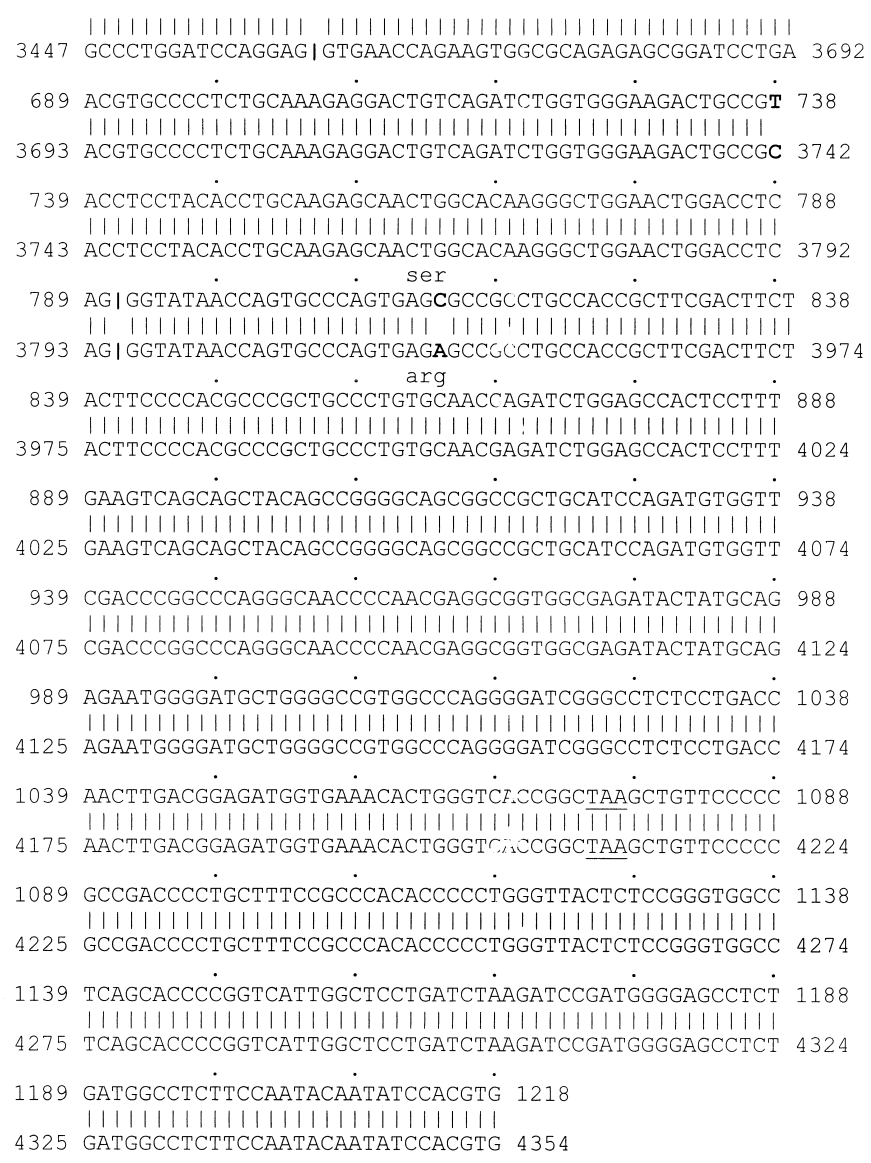

Fig. 1. (Continued)

mFBP gene were thus obtained and resultant cosmid DNAs were purified and sequenced using automated sequencing (ABI 377, Perkin Elmer, Foster City, CA). The 3' end of the gene for mFBP was obtained by rescreening the YAC subclones using primers specific to the $3^{\prime}$ end of the mFBP cDNA. The resulting positive cosmid clone contained only the $3^{\prime}$ end of the gene. To obtain the intervening mFBP sequence, primers based on the previously obtained gene sequence and the mFBP cDNA (Table 1) were used to amplify a portion of the missing region using the YAC clone as template. PCR generated DNA was cloned into the PCRII vector according to the directions included with the kit and resultant colonies were screened using the same primers used for amplification. Positive colonies were completely sequenced in both directions. At least three positive colonies for each fragment were sequenced to reduce PCR generated errors. To obtain the remaining $3^{\prime}$ portion of the mFBP gene, a BAC library was screened by hybridization using a probe specific to the $3^{\prime}$ end of the mFBP gene [5]. A positive mFBP BAC clone was digested with PST1 and EcoR1 and a fragment containing the missing region of the mFBP gene was cloned into PBSIISK. The 


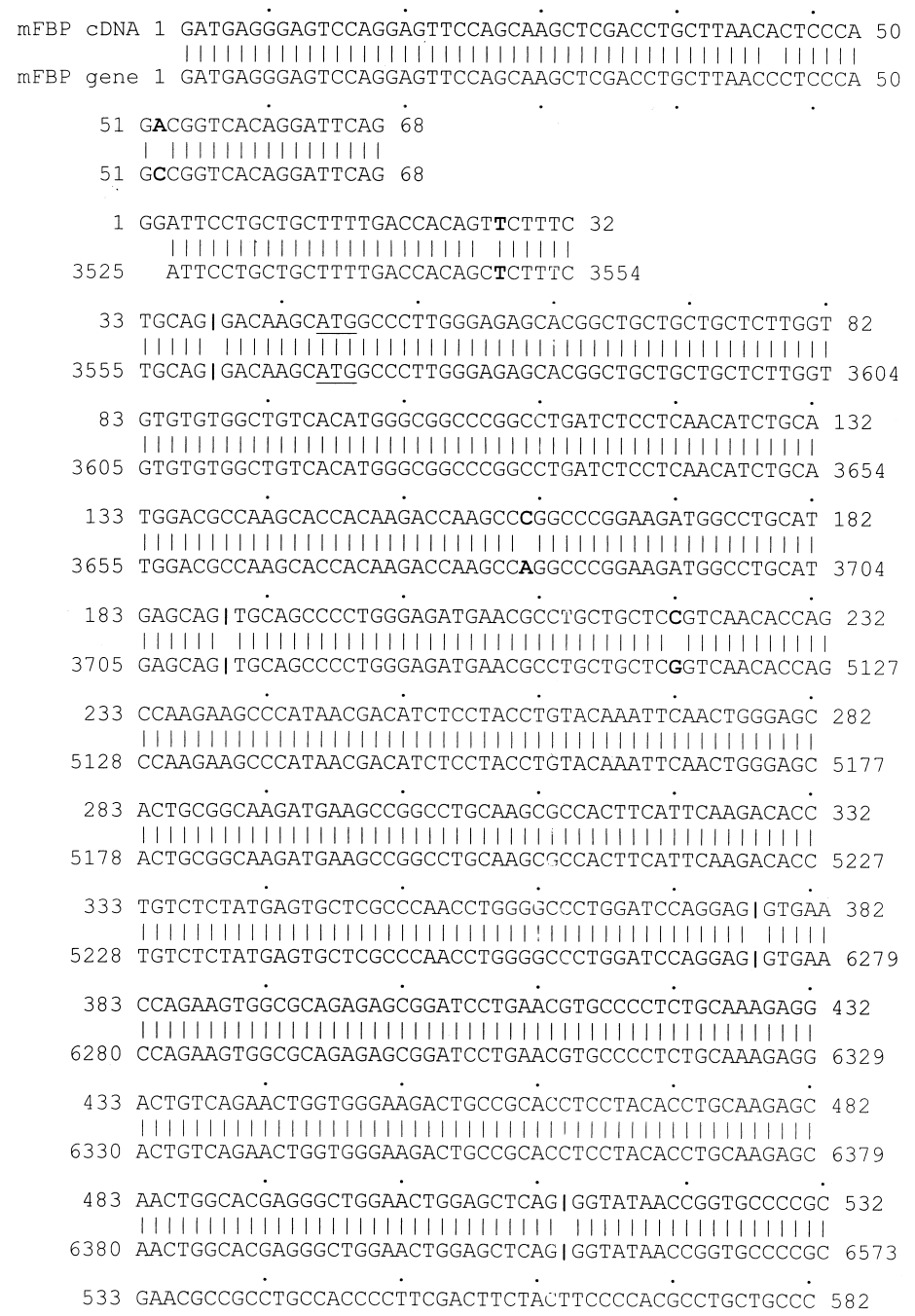

Fig. 1. (Continued)

region containing the missing $3^{\prime}$ portion of the $\mathrm{mFBP}$ gene was then sequenced using automated sequencing.

\section{Results}

Both the sFBP and mFBP genes were isolated from the same YAC clone, and sequencing of the cosmid containing the $5^{\prime}$ end of the mFBP gene resulted in sequence matching the $3^{\prime}$ end of the sFBP gene. These results indicate that the two genes must be very close (within $\sim 50 \mathrm{~kb}$ of each other), with the sFBP gene $5^{\prime}$ to the mFBP gene, a result which is similar to the human FBP/FR locus [9]. The sFBP and mFBP gene sequences obtained are shown 


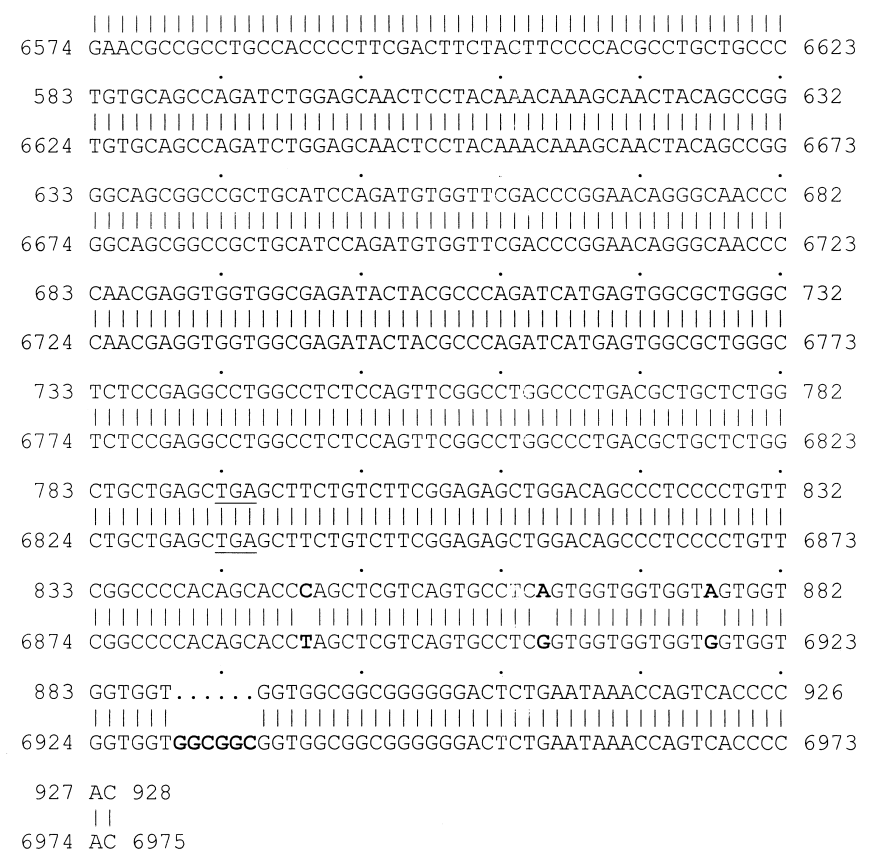

Fig. 1. (Continued)

aligned with their corresponding cDNAs in Fig. 1. The genes were 99.2 and $99.1 \%$ identical with the previously determined cDNA sequences, respectively. Each gene consisted of 5 exons and 4 introns. The few mismatches that were present are likely to be the result of polymorphisms occurring between animals. Of the differences between the cDNA and gene sequences, most do not result in changes in the coding sequence. One exception is a $\mathrm{C}$ to $\mathrm{A}$ change (base 913 of the cDNA) which in the sFBP gene codes for an arginine instead of a serine. The sequences obtained for the sFBP and mFBP genes spanned 6.2 and $9.1 \mathrm{kbp}$, respectively, including 4.4 and $7.0 \mathrm{kbp}$, respectively, corresponding to each cDNA, and approximately 1.4 and $1.8 \mathrm{kbp}$, respectively, of the $5^{\prime}$ proximal regions for each gene.

Fig. 2 compares the structure of the genes for porcine secreted and membrane folate binding proteins with each other and with the structures of other known FBP/FR genes from other species. The structures of all the FBP/FR genes were very similar for the last three exons of each gene; the sizes and the positions of splice junctions for the last three exons are similar in all genes. Both porcine genes contained multiple copies of a swine SINE [10] repeat element (Fig. 3). Furthermore, comparison of introns 3 and 4 of both genes indicated that both the last two introns contained regions of significant sequence homology between sFBP and mFBP (85-92\%), while homology was much less between the porcine and human genes in this region (Fig. 3 and 4). In contrast to the $3^{\prime}$ end of the gene, the sizes of the exons in the $5^{\prime}$ end of the gene were more variable and sequence homology within the introns between these exons occurred between species but was FBP/FR form specific (see below). Table 2 indicates the sequences found at the splice junctions for sFBP and mFBP. These sequences match the consensus splice donor (NNG gt(a/g)agn) and acceptor (cag NNN) 


\section{Porcine Endometrial Secreted Folate Binding Protein}
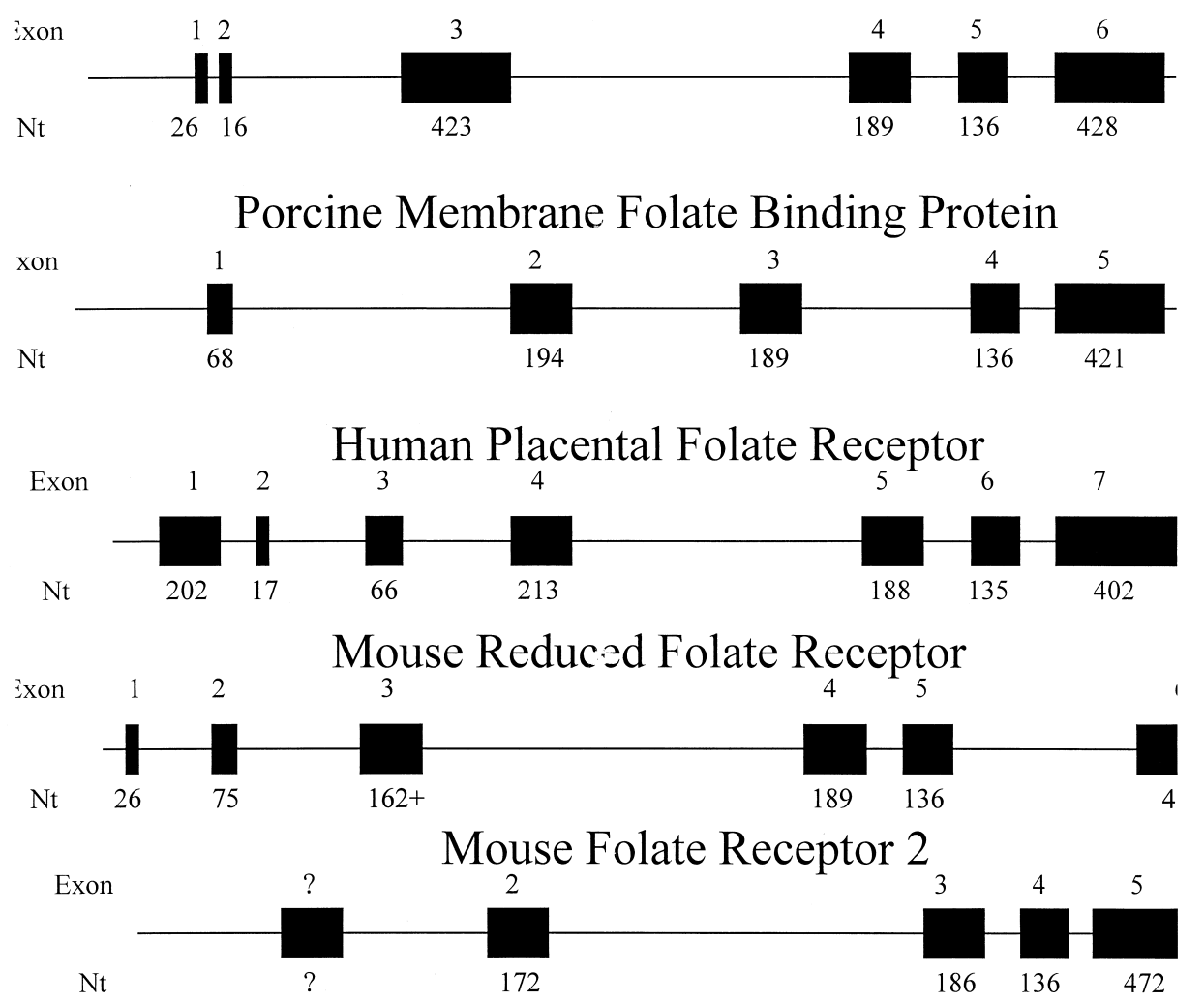

Fig. 2. Schematic diagrams of the porcine sFBP and mFBP genes are illustrated along with the structures of human $\alpha$-folate receptor [13] and mouse folate receptor 1 [21] and 2 [22]. All gene structures are similar for the last three exons.

sequences that have been obtained for mammals [11]. Finally, the sequence beginning exon 1 of the sFBP gene and exon 2 of the mFBP gene share some homology with the consensus sequence (YAYTCYYY, Y = pyrimidine, sFBP has three mismatches, exon 2 of the mFBP gene has one mismatch) for initiator regions for transcription [12]. The beginning of exon 1 of the mFBP gene has no homology to this sequence.

Significant sequence homology was present in the $5^{\prime}$ proximal regions and/or the first introns of the secreted and membrane FBP genes when they were compared with similar regions present in the human secreted $(\gamma)$ and placental $(\alpha)$ forms of FBP/FR, respectively (Fig. 3, 5, 6). For sFBP, sequence homology was found both $5^{\prime}$ and $3^{\prime}$ of exon 1 of the sFBP gene, while the sequence of exon 1 itself did not display significant homology (Fig. 5). Curiously, intron 1 of the sFBP gene is homologous to the $5^{\prime}$ proximal region of the $\mathrm{h} \gamma \mathrm{FBP}$ gene (i.e., the region upstream of the first exon of $h \gamma \mathrm{FBP}$ ). A swine SINE repeat element appears to have been inserted into the sFBP gene at or near the region homologous to the transcription start site of $\mathrm{h} \gamma \mathrm{FBP}$, possibly disrupting transcription from this site. 


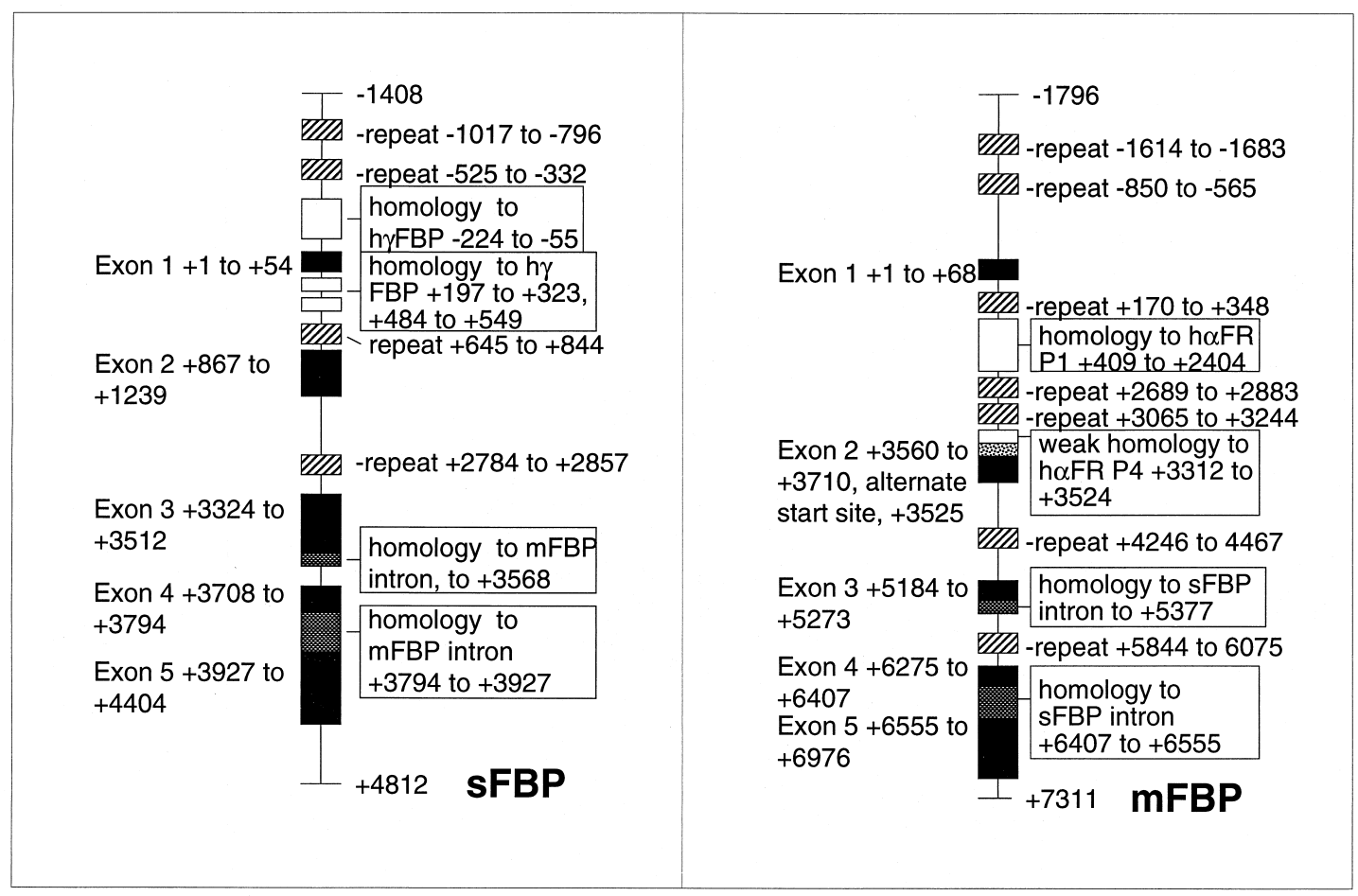

Fig. 3. Schematic diagrams of the sFBP and mFBP genes indicating the positions of exons (black boxes) repeat regions (hatched boxes), regions of homology with human genes (open boxes), and intronic regions of homology between the two porcine genes (dotted boxes).

For the mFBP gene, significant homology with $h \alpha \mathrm{FR}$ was present in the first intron of $\mathrm{mFBP}$ only, and the region in the $\mathrm{h} \alpha \mathrm{FR}$ sequence that is homologous to mFBP includes both the P1 and P4 promoters previously identified for that gene [13]. There was no homology to the human $\alpha$ FR sequence found for the region $5^{\prime}$ to exon 1 of the mFBP gene. These results suggest that at least two promoter regions are likely present in the mFBP gene, one corresponding to the $\mathrm{P} 4$ promoter region in the human gene, and one different from any that has been previously described. A comparison of sFBP and mFBP genes in the regions near the start of transcription showed that no homology between the two genes was present in this region, suggesting that the $5^{\prime}$ proximal regions of each gene are specific to each different form of FBP.

\section{Discussion}

The complete nucleotide sequences for the porcine sFBP and mFBP genes provides an explanation for the different $\mathrm{mRNAs}$ for $\mathrm{mFBP}$ that have been obtained previously [5] and allows a comparison of these two genes with each other, and with the corresponding genes of humans. These comparisons suggest several hypotheses regarding FBP/FR genes gener- 
Table 2

The splice donor and acceptor sites for the secreted and membrane folate binding protein genes are listed for each splice junction

\begin{tabular}{llll}
\hline Secreted FBP & Donor sequence & Pyrimidine stretch & Acceptor sequence \\
\hline Exon 1 to Exon 2 & GAG|gtaagg & $8 \mathrm{bp}$ & cag|GAGCCT \\
Differential splice* & GGG|gtaagc & $6 \mathrm{bp}$ & cag|AAGTGG \\
Exon 2 to Exon 3 & CAG|gtgagg & $9 \mathrm{bp}$ & cag|TGCAGC \\
Exon 3 to Exon 4 & GAG|gtatag & $10 \mathrm{bp}$ & cag|GTGAAC \\
Exon 4 to Exon 5 & CAG|gtgagg & $8 \mathrm{bp}$ & cag|GGTATA \\
$\begin{array}{l}\text { Membrane FBP } \\
\text { Exon } 1 \text { to Exon 2 }\end{array}$ & CAG|gtatgg & $8 \mathrm{bp}$ & cag|GACAAG \\
Exon 2 to Exon 3 & CAG|gtgggc & $12 \mathrm{bp}$ & cag|TGCAGC \\
Exon 3 to Exon 4 & GAG|gtacag & $10 \mathrm{bp}$ & cag|GTGAAC \\
Exon 4 to Exon 5 & CAG|gtgagg & $8 \mathrm{bp}$ & cag|GGTATA \\
\hline
\end{tabular}

* Splicing variant reported in Vallet et al. (5).

ally, and about the control of each specific gene type. First, the heterogeneous $5^{\prime}$ untranslated regions found previously for the $\mathrm{mFBP} \mathrm{cDNA}$ are the result of initiation of transcription of the gene from two different initiation sites. Second, the remarkably high conservation of regions within the last two introns of the sFBP and mFBP genes suggests that these introns contain sequences that may influence some aspect of the function of both FBP genes. Third, the regions of homology with similar regions in the h $\alpha \mathrm{FR}$ and $\mathrm{h} \gamma \mathrm{FBP}$ genes near the $5^{\prime}$ end of each porcine FBP gene suggests that these regions contain type specific sequences that control the function of each gene type.

It was previously reported that the $5^{\prime}$ untranslated regions (UTR) of both the sFBP and mFBP mRNAs were heterogeneous [5]. For sFBP, the heterogeneity appeared to be due to the differential splicing of a region within the sFBP mRNA. The current results indicate that this region is contained within Exon 2 of the sFBP gene, lending support to the concept of differential splicing within Exon 2 versus an alternative exon 2 . For $\mathrm{mFBP}$, the heterogeneity in the 5' UTR of the mRNAs appears to be due to initiation of transcription from two different sites within the mFBP gene, which are separated by a large (3456 bp) intron. Sequence homology to both the P1 and P4 promoter regions for $h \alpha F R$ are contained within this intron and these homologous regions appear to be separated from one another by the insertion of two swine SINE repeat elements. One of the two different 5' UTRs obtained for mFBP mRNA appears to correspond well to initiation of transcription from the human P4 promoter (corresponding to FB4 cDNA; 13), despite the fact that this region of the gene was only weakly homologous to the P4 region of the hFR gene. Saikawa et al., [14] reported that the activity of the P4 promoter region was strongly influenced by a cluster of two Sp1 binding sites and a CAC/Sp1 binding site near the transcription initiation site for the KB4 mRNA. Sequence alignment of this region with the mFBP gene indicated that none of these sites are well conserved in the mFBP gene. However, signal scan analysis [15] of this region indicates the presence of a possible Sp1 binding site [16] and a possible CAC binding site $[17,18]$ within the region, both are close to the position of their counterparts in the $h \alpha \mathrm{FR}$ gene [14]. Whether these regions or other regions influence the rate of transcription from this site requires further study. 


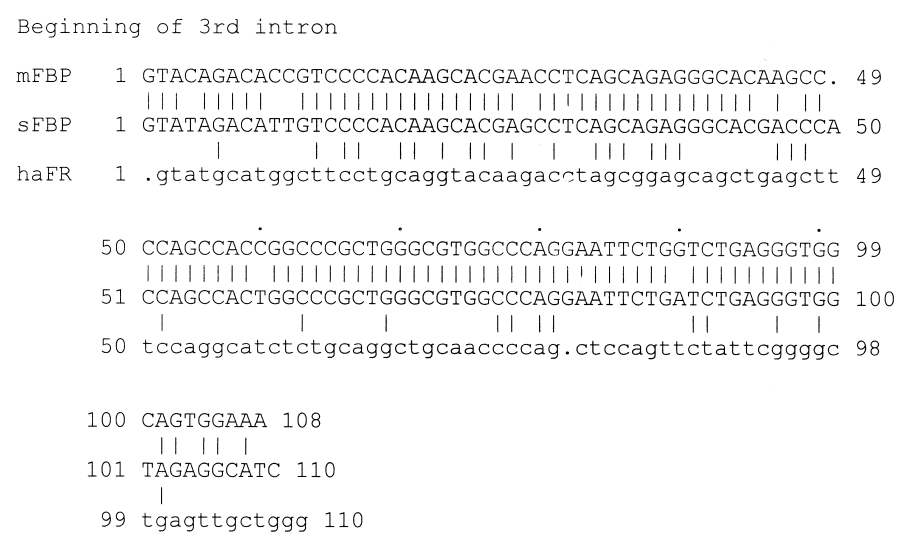

4 th intron

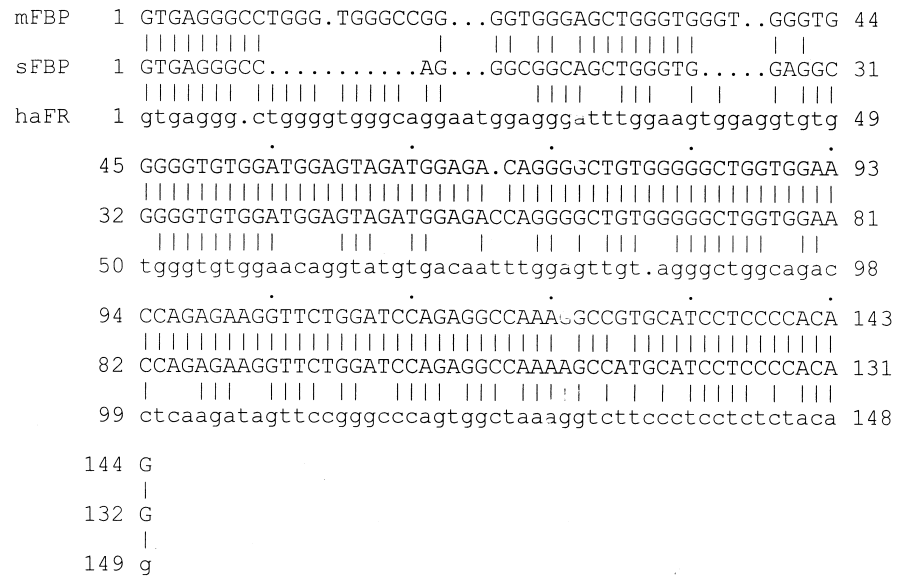

Fig. 4. Alignments of sequences found in the $3^{\text {rd }}$ and $4^{\text {th }}$ introns of the sFBP, mFBP and human $\alpha$ genes are illustrated. Underlined areas are repeated regions, bold areas are palindromic.

Curiously, despite significant sequence homology between the mFBP gene and the P1 promoter region of the $\mathrm{h} \alpha \mathrm{FR}$ gene, no transcripts were observed that originate from this region. It is possible that the insertion of repeat elements into this region disrupted transcription from these sites. However, several of the sites of mRNA initiation for the h $\alpha \mathrm{FR}$ gene are $100 \%$ conserved in the $\mathrm{mFBP}$ gene, as is the splice junction corresponding to the end of exon 1 of the h $\alpha \mathrm{FR}$ gene. The high sequence homology in this region combined with the intact splice junction makes it likely that transcription probably does originate from these regions of the gene in some tissues. Thus, other possible explanations for the lack of a corresponding cDNA for this region may be that either the transcripts have not yet been detected due to the methods used previously [5] or that this promoter region may not be 


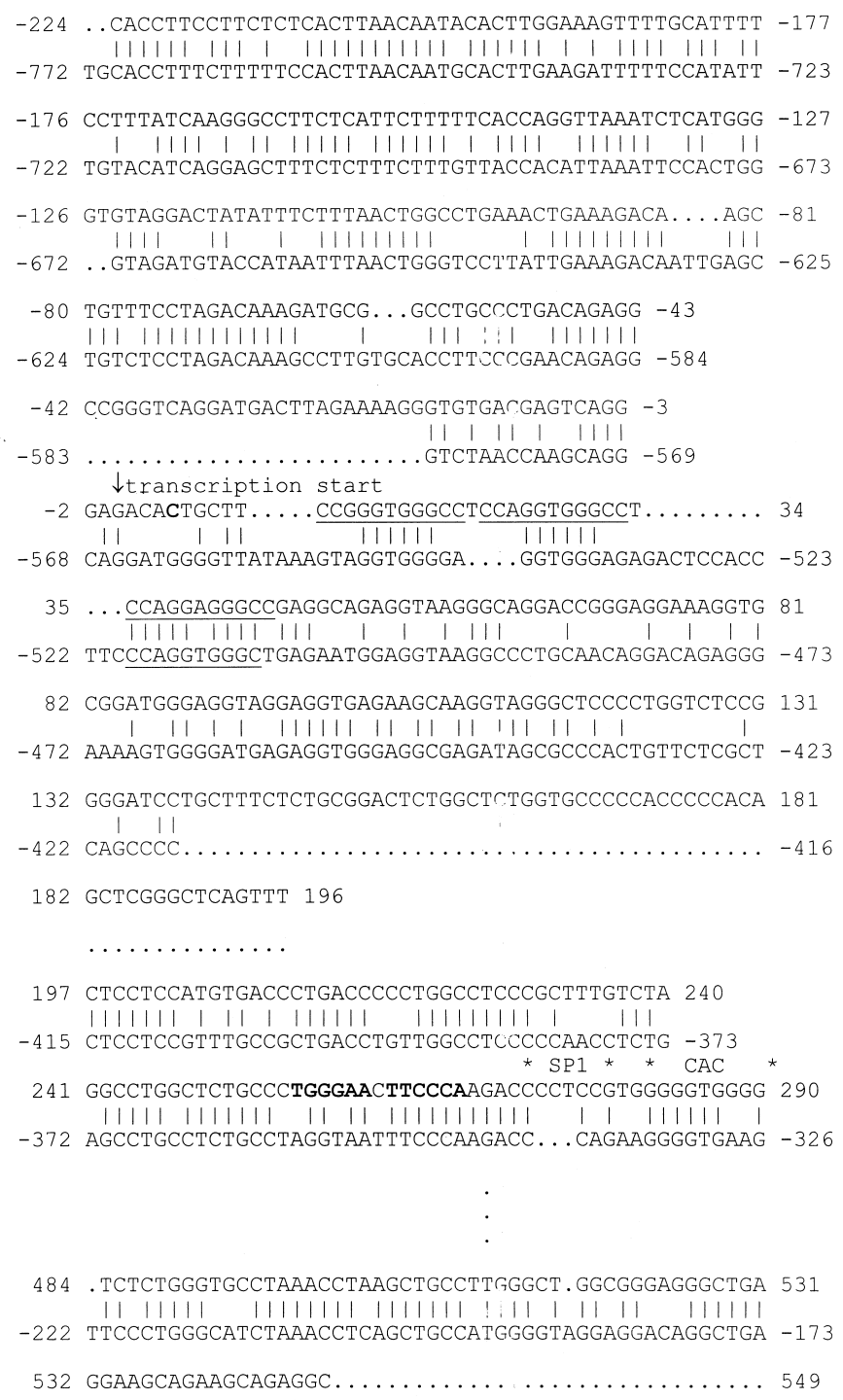

Fig. 5. The 5' regions of the sFBP and human $\gamma \mathrm{FBP}$ genes are aligned to indicate homologies between the two genes. Repeat sequences are underlined, palindromic sequences are in bold letters. Transcription start sites for each gene are indicated.

active in the endometrium of the pig. The mRNA corresponding to initiation of transcription from this promoter region may occur in other tissues. Elwood et al., [13] reported that the activity of this promoter is specific to kidney and cerebellum. Resolution of this question will require the cloning and sequencing of $\mathrm{mFBP}$ transcripts from a variety of tissues, to determine if the region corresponding to the P1 promoter is active in other tissues in swine.

Surprisingly, Exon 1 of the mFBP gene is found $5^{\prime}$ to the regions showing homology to the $\mathrm{P} 1$ and $\mathrm{P} 4 \mathrm{~h} \alpha \mathrm{FR}$ promoter regions, suggesting that a third promoter region may lie in the 


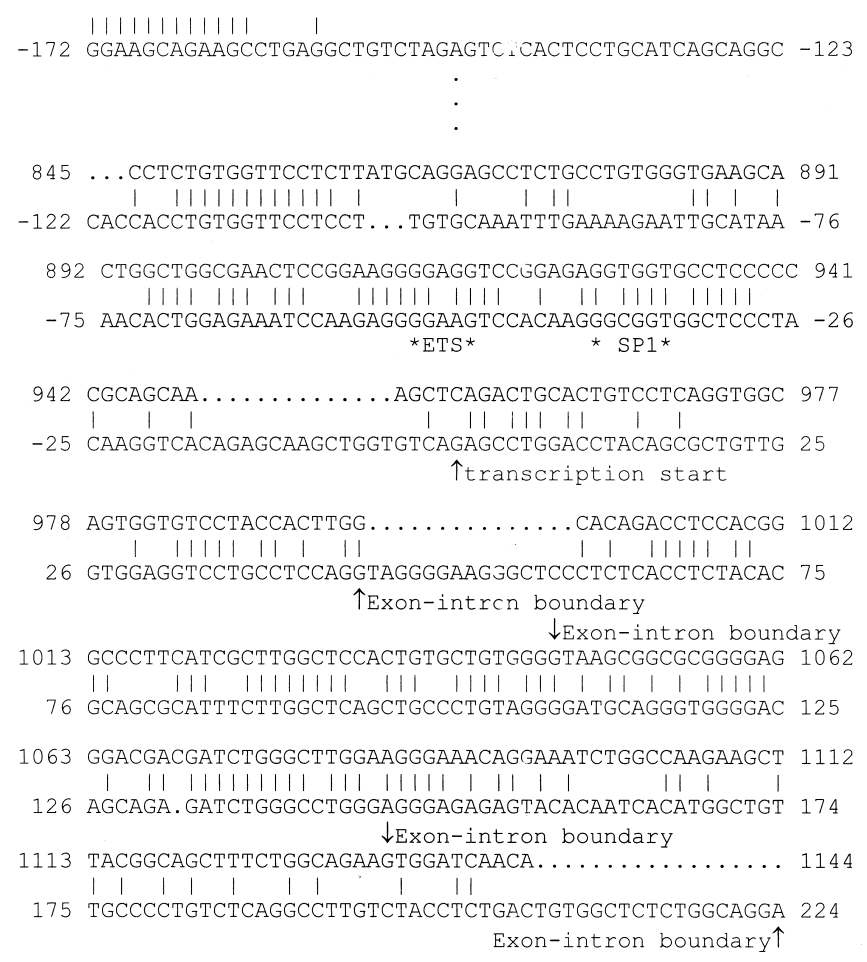

Fig. 5. (Continued)

region 5' of Exon 1. Several Sp1 sites [16] are located in the region between exon 1 and the repeat region that occurs $\sim 500$ base pairs upstream of the start of transcription. Two regions containing direct repeats and appearing to contain clusters of transcription factor binding sites are located in this region, one from -132 to -101 and another from -260 to -243 . The first contains a TGGGGGA direct repeat; using signal scan, the first TGGGGGA is part of a potential binding site for CAC binding factor, along with flanking Sp1 sites. Thus, this site is similar to the Sp1 and CAC sites previously shown to be involved in the control of the P4 promoter [14]. The second region contains tandem CACCTCC sequences flanking a CAAT sequence. The CACCTCC sequence was found in two regions of the collagen II gene known to contain silencer elements [19], however it has not been shown directly that this sequence is responsible for the silencer activity. There is also a third direct repeat of the sequence GAAGCT between these two sites which does not appear to correspond to a known transcription factor binding site. Determination of the role of these and other sequences in this region in transcription of the mFBP gene from exon 1 requires further study.

Significant sequence homology also occurred between the sFBP and h $\gamma \mathrm{FBP}$ genes. However, the start of transcription of the sFBP gene is not homologous to the start of transcription of the $h \gamma \mathrm{FBP}$ gene [20]. A region homologous to the start of transcription of the $\mathrm{h} \gamma \mathrm{FBP}$ gene is found within the sequence of exon 2 of the sFBP gene. The region directly $5^{\prime}$ of the h $\gamma \mathrm{FBP}$ gene has been shown to contain promoter activity and two transcription factor binding sites, an ets and an Sp1 site, have been shown to influence the level of 


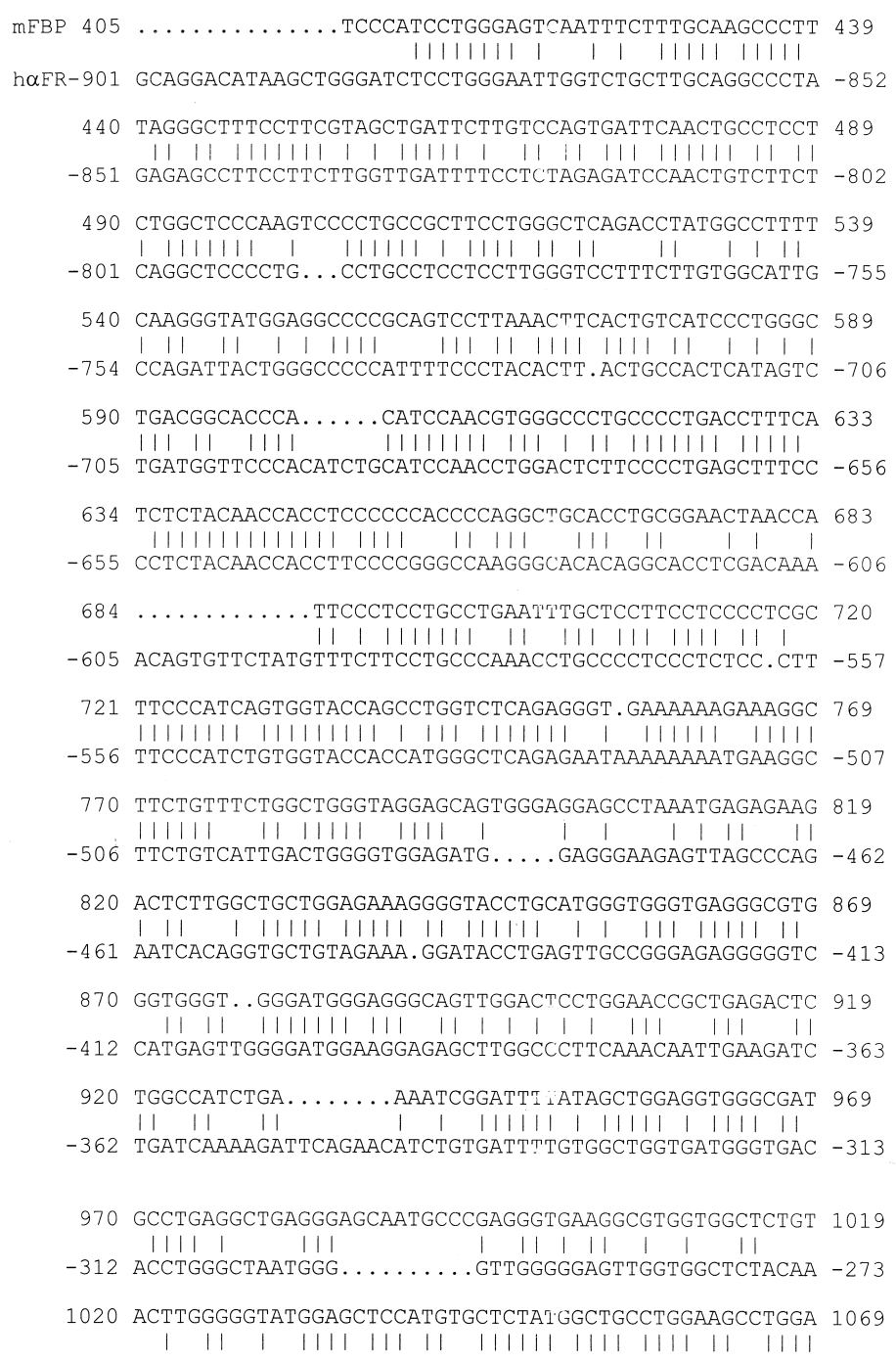

Fig. 6. The 5' regions of the mFBP and human $\alpha$ FR genes are aligned to indicate homologies between the two genes. Transcription start sites for each gene are indicated. mRNA splicing junctions are indicated with bold, underlined letters.

transcription [20]. These two sites are not conserved in the sFBP gene. Furthermore, a repeat region appears to have become inserted into this region in the sFBP gene, and may further explain the lack of transcription from this region in the sFBP gene. Curiously, exon 1 of the sFBP gene contains a triple nearly perfect direct repeat with the sequence $\mathrm{CC}(\mathrm{A} / \mathrm{G}) \mathrm{GG}(\mathrm{T} /$ A)GGGCC. Using signal scan analysis, two of the three repeats are candidates for CAC binding protein binding sites [18]. The arrangement of this triple tandem repeat combined with the sequence of the repeat itself creates two $11 \mathrm{bp}$ nearly perfect palindromic sites. Because this region is transcribed, it could influence mRNA function or stability as well as 


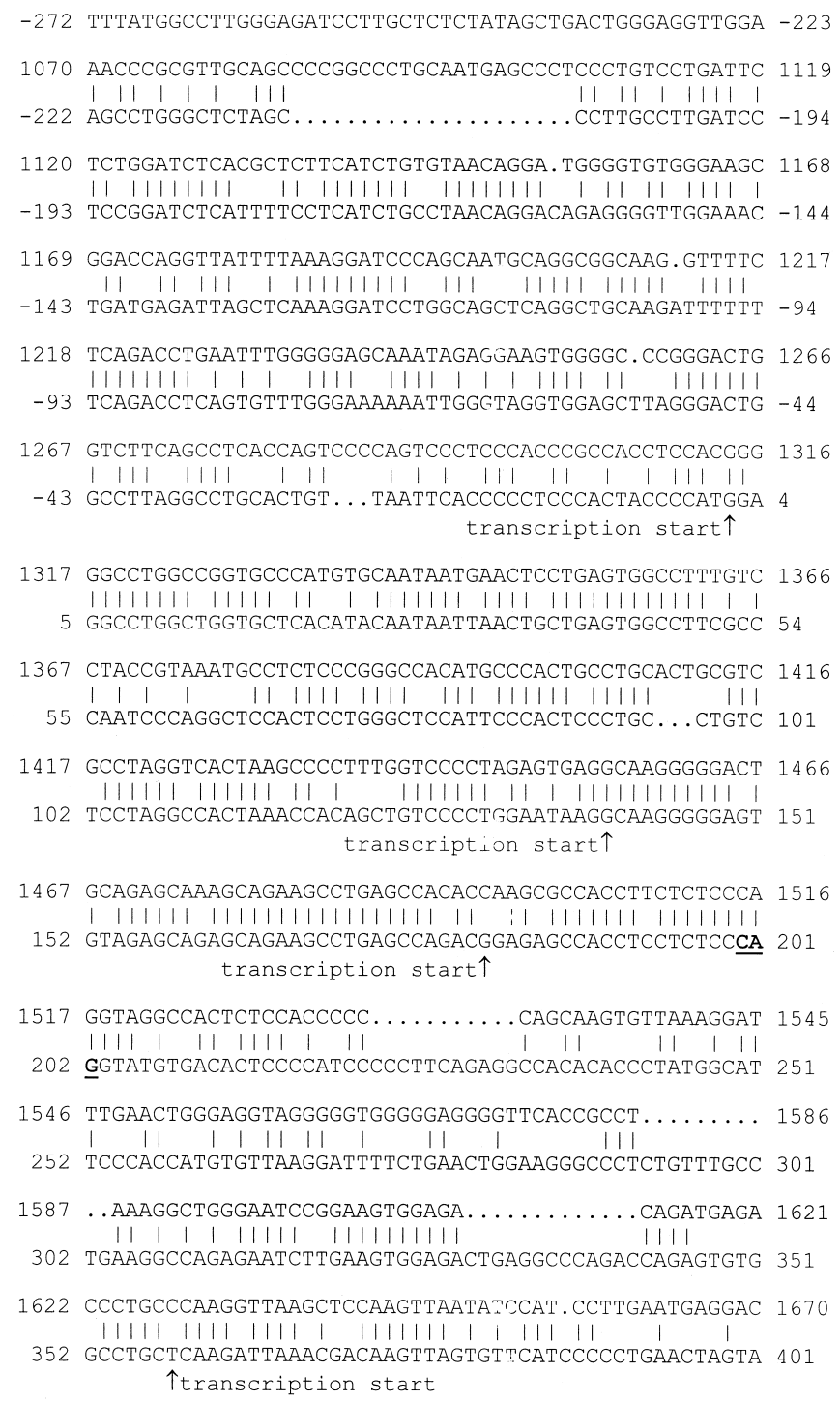

Fig. 6. (Continued)

mRNA transcription. Interestingly, only two of the three repeats were obtained in the sFBP cDNA described previously (Fig. 1; Fig. 4). This discrepancy between the mRNA and the gene could be the result of artifactual elimination of the third repeat in bacteria during cloning of the cDNA, or possibly may be the result of a polymorphism between individual pigs in the number of repeats present in this region. We are currently exploring these possibilities. Further possible sites involved in the control of transcription could be within the regions homologous to the $\mathrm{h} \gamma \mathrm{FBP}$ in intron 1 . There is a moderately conserved palindromic site followed by an Sp-1 site and a potential CAC binding site within this region, the latter two again being similar to the region known to influence the $\mathrm{P} 4$ promoter region of the h $\alpha \mathrm{FR}$ 


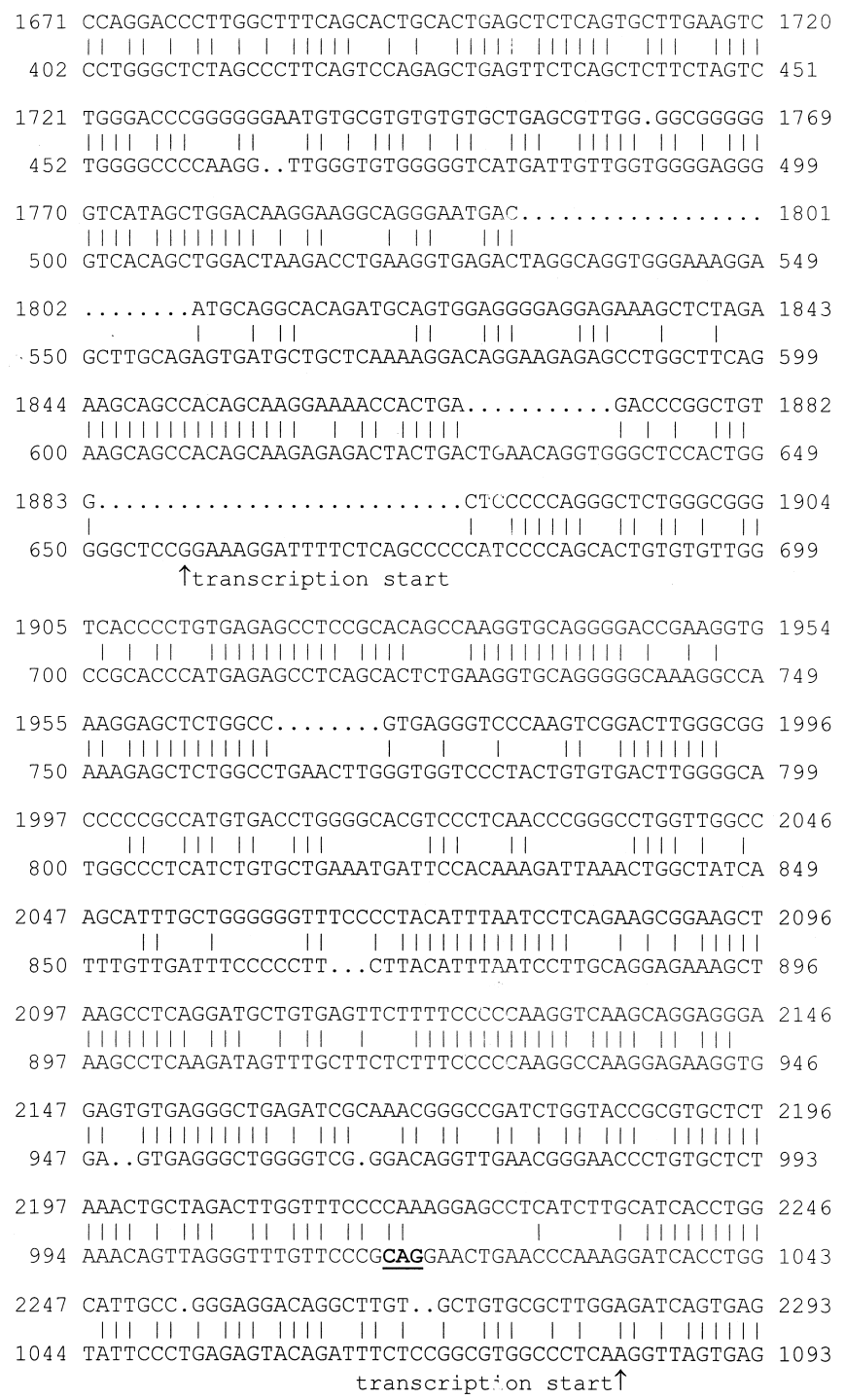

Fig. 6. (Continued)

gene [14]. Finally, there is a short region of homology between the sFBP and h $\gamma$ FBP genes in the region $5^{\prime}$ of exon 1 . Further upstream are two repeat regions. Using signal scan analysis, there are very few potential binding factor sites within this upstream homologous region. The actual role of each of these regions in the control of transcription and/or translation awaits further work.

The high homology between regions in the $3^{\text {rd }}$ and $4^{\text {th }}$ intron of the two porcine FBP/FR genes suggests that these regions contain elements that control transcription or mRNA processing. Within the homologous region of the third exon, there are two completely conserved partial palindromic sites. Also, this region of the sFBP gene contains four 


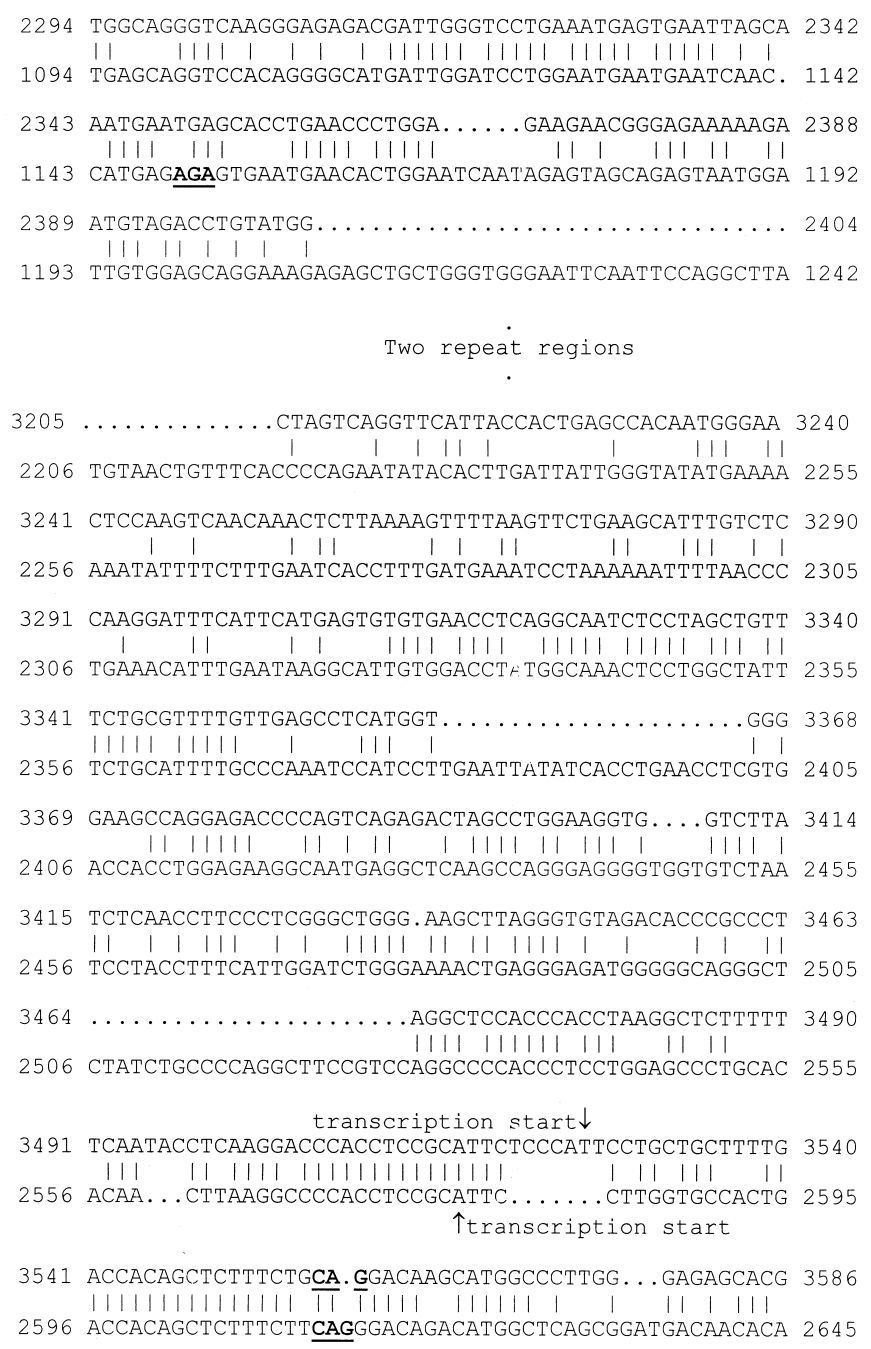

Fig. 6. (Continued)

nearly perfect repeats of the sequence CACNAGC and these are partially conserved in mFBP. For exon 4, there is a single partial palindromic sequence, two repeats of the sequence GATGGAG and two repeats of the sequence GGGGCTG, all of which are completely conserved between the two genes. Curiously, these regions are more highly conserved between the genes of the pig than between the genes of the pig and the corresponding gene in the human (Fig. 4). This suggests that these regions control functions of both genes that may be specific to swine. Some or all of these regions could bind transcription enhancing factors that influence the rate of transcription of both genes.

In conclusion, the genes for porcine endometrial secreted and membrane forms of folate binding protein have been characterized and the sequences were compared with each other and with the sequences of the corresponding human genes. The structures of the two genes 
are similar to the other known FBP/FR genes. The sequence of the $5^{\prime}$ proximal region and intron 1 of the gene for the secreted form of FBP is homologous to the putative promoter region of the human $\gamma \mathrm{FBP}$ gene, suggesting the possibility that this region may contain elements that control transcription of this gene. Likewise, similar homologous regions exist between the mFBP gene and human $\alpha \mathrm{FR}$. This homology coupled with the divergence in the 5' UTR of the mFBP gene strongly suggest that at least two promoter regions are present within this gene. Finally, highly conserved sequence homology within the third and fourth introns of both porcine genes suggests the possible presence of controlling elements within these introns.

\section{Acknowledgments}

Names are necessary to report factually on available data; however, the USDA neither guarantees nor warrants the standard of the product, and the use of the name by USDA implies no approval of the product to the exclusion of others that may also be suitable.

\section{References}

[1] Shane B, Stokstad EL. Vitamin B12-folate interrelationships. Annu Rev Nutr 1985;5:115-41.

[2] Babior BM. Erythrocyte disorders: anemias related to disturbance of DNA synthesis (megaloblastic anemias). In: Hematology, $4^{\text {th }}$ ed. Williams WJ, Beutler E, Erslev AJ and Lichtman MA (eds.) McGrawHill, Inc., New York, NY, p. 453-81, 1990.

[3] Thenen SW. Gestational and neonatal folate deficiency in rats. Nutr Res 1991;11:105-16.

[4] Vallet JL, Christenson RK, Klemcke HG. Purification and characterization of intrauterine folate binding proteins from swine. Biol Reprod 1998;59:176-81.

[5] Vallet JL, Smith TPL, Sonstegard T, Pearson PL, Christenson RK, Klemcke HG. Isolation of complementary deoxyribonucleic acids encoding putative secreted membrane-bound folate binding proteins from endometrium of swine. Biol Reprod 1999;61:372-9.

[6] Vallet JL, Christenson RK, Klemcke HG. Technical Note: A radioimmunoassay for porcine intrauterine folate binding protein. J Anim Sci 1999;77:1236-40.

[7] Van Hoozen CM, Ling E-H, Halsted CH. Folate binding protein: molecular characterization and transcript distribution in pig liver, kidney and jejunum. Biochem J 1996;319:725-9.

[8] Moran P, Raab H, Kohr WJ, Caras IW. Glycophospholipid membrane anchor attachment, molecular analysis of the cleavage/attachment site. J Biol Chem 1991;266:1250-7.

[9] Ragoussis J, Senger G, Trowsdale J, Campbell IG. Genomic organization of the human folate receptor genes on chromosome 11q13. Genomics 1992;14:423-30.

[10] Singer DS, Parent LJ, Ehrlich R. Identification and DNA sequence of an interspersed repetitive DNA element in the genome of the miniature swine. Nucleic Acids Res 1987;15:2780.

[11] Burge CB, Tuschl T, Sharp PA. Splicing of precursors to mRNAs by the spliceosomes. In: The RNA World, $2^{\text {nd }}$ ed. Gesteland RF, Cech TR and Atkins JF (eds). Cold Spring Harbor Laboratory Press, Cold Spring Harbor, NY, p. 525-560, 1999.

[12] Roeder RG. The complexities of eukaryotic transcription initiation: regulation of preinitiation complex assembly. Trends Biol Sci 1991;16:402-11.

[13] Elwood PC, Nachmanoff K, Saikawa Y, Page ST, Pacheco P, Roberts S, Chung K-N. The divergent 5' termini of the á human folate receptor (hFR) mRNAs originate from two tissue-specific promoters and alternative splicing: Characterization of the á hFR gene structure. Biochemistry 1997;36:1467-78. 
[14] Saikawa Y, Price K, Hance KW, Chen TY, Elwood PC. Structural and functional analysis of the human KB cell folate receptor gene P4 promoter: cooperation of three clustered Sp1-binding sites with initiator region for basal promoter activity. Biochemistry 1995;34:9951-61.

[15] Prestridge DS. Signal scan: A computer program that scans DNA sequences for eukaryotic transcriptional elements. Comput Appl Biosci 1991;7:203-6.

[16] Kadonga JT, Jones KA, Tjian R. Promoter-specific activation of RNA polymerase II transcription by Sp1. Trends Biol Sci 1986;11:20-3.

[17] Schule R, Muller M, Otsuka-Murakami H, Renkawitz. Cooperactivity of the glucocorticoid receptor and the CACCC-box binding factor. Nature 1988;332:87-90.

[18] Yu C.-Y, Motamed K, Chen J, Bailey AD, Shen C-KJ. The CACC box upstream of human embryonic $\epsilon$ globin gene binds Sp1 and is a functional promoter element in vitro and in vivo. J Biol Chem 1991;266: 8907-15.

[19] Savagner P, Miyashita T, Yamada Y. Two silencers regulate the tissue-specific expression of the collagen II gene. J Biol Chem 1990;265:6669-74.

[20] Wang H, Ross JF, Ratnam M. Structure and regulation of a polymorphic gene encoding folate receptor type $\gamma / \gamma^{\prime}$. Nuc Acids Res 1998;26:2132-42.

[21] Tolner B, Roy K, Sirotnak FM. Organization, structure and alternate splicing of the murine RFC-1 gene encoding a folate transporter. Gene 1997;189:1-7.

[22] Brigle KE, Seither RL, Westin EH, Goldman ID. Increased expression and genomic organization of a folate-binding protein homologous to the human placental isoform in L1210 murine leukemia cell lines with a defective reduced folate carrier. J Biol Chem 1994;269:4267-72. 